menses in each patient, one before treatment, two while on ethamsylate $(500 \mathrm{mg}$ four times daily from five days before the anticipated onset of menstruation for 10 days) and two while on indistinguishable doses of placebo with double-blind random allocation of each of the tablets. The Wilcoxon signed rank test was used in statistical analysis of the results. Mean blood loss was $64.8 \mathrm{ml}$ before treatment and $64.6 \mathrm{ml}$ during placebo therapy $(P>0.10)$ but was significantly less $(53.5 \mathrm{ml} ; P<0.05)$ during administration of ethamsylate. The mean percentage reduction in blood loss was $18 \cdot 6 \pm 4 \cdot 7$, giving a range at the $95 \%$ confidence level of $8 \cdot 4-28 \cdot 8$.

Such results, if confirmed by a longer series, would suggest that a patient with an IUD in situ who complained of menorrhagia should be offered ethamsylate as primary treatment. This could prove sufficiently effective in controlling the cycle to make further manipulation unnecessary.

ROBERT F HARRISON $S$ CAMPBELL

Institute of Obstetrics and Gynaecology,

Queen Charlotte's Hospital,

London W6

Jaffe, G, and Wickham, A, fournal of International
Medical Research, 1973, 2, 127.

\section{Computers and privacy}

SIR,-In your leading article on this subject (24 January, $p$ 178) you seem to regard the Swedish data protection law as an almost ideal model. Some further information is needed. The Swedish Government Data Inspectorate and the data protection law mainly deal with securing the data banks against undue commercial infringement and also with checking the accuracy of the information stored. Very little has been done to avoid undue governmental infringement of the registers-that is, to prevent one agency from using data stored by another agency for a different purpose.

The Swedish National Health Security Board has by now constructed gigantic data banks of all Swedish inhabitants, easily identified by the unique 10-figure person identification number. Even extremely sensitive facts about individuals are now accessible to other public agencies, such as police and taxation officials, not primarily concerned about health and sick care. In many ways the foundation of the Government Data Inspectorate has increased the threat to privacy as it has made it easier to make different computerised registers compatible.

In Sweden nowadays 1984 does not seem so far away as eight years.

Eva BERgQvist

\section{Hallstahammar,}

Sweden

\section{Encouragement of breast-feeding}

SIR,-In discussing this subject Dr E Eastham and others (7 February, p 305) conclude by suggesting "appropriate literature" and "a nurse with special training." They rightly stress an "educational approach" and "husband's advice" as well. I doubt if anyone would disagree. However complex the problem may be, I believe we can reverse the decline if we simply take a positive approach.

For over 18 months I have been involved in an active programme aimed at promoting breast-feeding. This may be summarised as follows. I talk to expectant parents in groups of 20 to 30 couples, well before the expectant dates. I try to explain the facts and figures about breast-feeding and artificial feeding and answer their queries. It is sometimes amazing to learn about the myths that surround infant feeding. The midwifery nursing staff maintains a positively charged environment in the maternity wards. They encourage the mothers and help them to breast-feed their infants.

On preliminary survey it appears that over $80 \%$ of the mothers who attended the talk breast-fed their babies during their stay in the maternity unit. In contrast, only $20 \%$ of those mothers who did not come to the talk breast-fed their infants. But on discharge from the hospital the incidence of breastfeeding dropped drastically in both groups over the next three to four weeks. We hope to reverse this decline with the forthcoming understanding and the co-operation of the district midwives and health visitors, who would try to maintain the positively charged environment in the homes and welfare clinics.

There is yet another group of parents in whom there is a family history of atopy. They are seen separately in smaller groups of 8-10. I talk to them on infant feeding in general and also stress the possible role of human milk in prevention of atopic diseases. The mothers are seen in groups two to three times before delivery and at intervals of two to four weeks after delivery. This is, in fact, a part of another prospective study. In this group, however, about $90 \%$ of the mothers start with breast-feeding and about $80 \%$ do it successfully for at least three months.

A longer period of study is evidently required before we can arrive at a legitimate conclusion. The preliminary result however, does suggest the following: (1) If a positive approach is taken by all concerned with infant wellbeing the decline of breast-feeding can be reversed. (2) There is a constant publicity on artificial feeding. This has to be matched with a similar publicity on breast-feeding. The family physicians, the welfare clinic doctors, and the health visitors can play the most important roles.

Bury General Hospital,

$S$ A HAIDER

Bury, Lancs

SIR,-Drs C J Bacon and J M Wylie (7 February, p 308) confirmed the usual factors found to be associated with successful breastfeeding, and their figures are comparable to my own unselected series of 302 cases from general practice. ${ }^{1}$ They note the increase in breast-feeding compared with the other Newcastle series of Dr E Eastham and his colleagues ( $p$ 305) studied some 18 months before, but they do not consider the probable part played by the DHSS report, Present-day Practice in Infant Feeding, ${ }^{2}$ which received very wide publicity in the period between. They imply that their patients were questioned in mid-1975 and the report came out in October 1974 , at an important time for most babies born in 1975 .

Mothers in my own practice have always been encouraged but not persuaded to breastfeed by doctor, health visitor, and midwife from early on in pregnancy. This encouragement was not intensified during 1974-5, yet there was a striking increase in breast-feeding which presumably followed the publicity given to the report.

\begin{tabular}{l|c|c|c|c|c|c|c}
\hline $\begin{array}{l}\text { Decided to } \\
\text { breast-feed } \\
(\%)\end{array}$ & 1969 & 1970 & 1971 & 1972 & 1973 & 1974 & 1975 \\
$\begin{array}{l}\text { Fully } \\
\text { breast- } \\
\text { feeding at } \\
\text { six weeks } \\
(\%)\end{array}$ & 24 & 52 & 46 & 48 & 57 & 48 & 59 \\
\hline
\end{tabular}

Recent further publicity against high-solute milks can be expected further to encourage breast-feeding.

Corsham, Wilts

Malcolm Aylett

\section{'Aylett, M J, Update, 1975, 10, 1133.}

Department of Health and Social Security, Present-day
Practice in Infant Feeding. Reports on Health and Social Subjects No 9. London, HMSO, 1974.

\section{Mobile resuscitation units}

SIR,-Your leading article on "First aid in acute myocardial infarction" (14 February, p 356) will, we hope, encourage further interest in the use of mobile resuscitation units in Britain. In the field of myocardial infarction the facts, as you say, speak for themselves. We should, however, like to reiterate our view that measures for resuscitation and immediate care are similar irrespective of the nature of the emergency.

The creation of a mobile resuscitation unit (MRU) requires enthusiasm, energy, time, and money together with an ability to push their merits through many committees. Our MRU was created in 1971 and combined with an active in-hospital training programme for ambulancemen. The report, shortly to be published, ${ }^{1}$ indicates the wide measure of acceptance once the unit was functioning. By creating an MRU to cover all suitable emergencies a better return for the financial investment is obtained and, more important, a better service is rendered to the public. Our MRU responds to 10-12 call-outs a week, of which $30 \%$ are for presumed myocardial infarction, $34 \%$ for accident victims, and $36 \%$ for other medical and surgical emergencies. Both the specially equipped ambulance and its staff (which includes the intensive treatment unit anaesthetist) have proved more than equal to the task of coping with the immediate care of all of these groups of patients.

We wholly support the proposal for more mobile units for myocardial infarction but suggest that there is no need to restrict the type of emergency to which such a unit may be called.

JOHN ZORAB

Department of Anaesthetics, PETER BASKETT Frenchay Hospital,

' Baskett, P J F, et al, British fournal of Anaesthesia. In press.

SIR,-The prospects for improving the outlook of those stricken with heart attacks, as depicted by Dr J R Hampton (24 January, p 201), are indeed bleak. Our view is more optimistic and is endorsed by the recent Royal College of Physicians/British Cardiac Society working party report which stated that mobile coronary care units should be further developed. ${ }^{1}$

Dr Hampton demonstrated that patients brought to hospital using a special alerting system had a different overall mortality (that 